\title{
Child Survival Strategies: Assessment of Knowledge and Practice of Rural Women of Reproductive Age in Cross River State, Nigeria
}

\author{
Aniekan Jumbo Etokidem ${ }^{1}$ and Ofonime Johnson ${ }^{2}$ \\ ${ }^{1}$ Department of Community Medicine, University of Calabar, Calabar 540001, Cross River State, Nigeria \\ ${ }^{2}$ Department of Community Medicine, University of Uyo, Uyo 520101, Akwa Ibom State, Nigeria
}

Correspondence should be addressed to Aniekan Jumbo Etokidem; etokidem@etokidem.com

Received 30 January 2016; Revised 11 July 2016; Accepted 12 July 2016

Academic Editor: Marcel Tanner

Copyright ( 2016 A. J. Etokidem and O. Johnson. This is an open access article distributed under the Creative Commons Attribution License, which permits unrestricted use, distribution, and reproduction in any medium, provided the original work is properly cited.

\begin{abstract}
Introduction. Nigeria is one of the five countries that account for about $50 \%$ of under-five mortality in the world. The objective of this study was to assess the knowledge and practice of child survival strategies among rural community caregivers in Cross River State of Nigeria. Materials and Methods. This descriptive cross-sectional survey used a pretested questionnaire to obtain information from 150 women of reproductive age. Data analysis was done using SPSS version 20. Results. The child survival strategy known to most of the respondents was oral rehydration therapy as indicated by $98 \%$ followed by female education by $73.3 \%$ and immunization by $67.3 \%$. Only $20 \%$ of the respondents had adequate knowledge of frequency of weighing a child while only $32.7 \%$ knew that breastfeeding should be continued even if the child had diarrhea. More respondents with nonformal education (83.3\%) practiced exclusive breastfeeding of their last children compared to respondents with primary education (77.3\%), secondary education $(74.2 \%)$, and tertiary education (72.2\%). Conclusion. Although respondents demonstrated adequate knowledge and practice of most of the strategies, there was evidence of gaps, including myths and misconceptions that could mar efforts towards reducing child morbidity and mortality in the state.
\end{abstract}

\section{Introduction}

Worldwide, nearly 6.6 million under-five children die yearly, translating to about 18,000 under-five deaths every day [1]. About $50 \%$ of under-five child deaths occur in only five countries of the world, namely, India, Nigeria, Democratic Republic of the Congo, Pakistan, and China. Two of these countries, India and Nigeria, account for more than onethird of global under-five mortality, contributing 22 percent and 13 percent, respectively [1]. Sub-Saharan Africa and Southern Asia countries are witnessing an increase in underfive mortality despite a drop from 32 percent in 1990 to 18 percent in 2012 in the rest of the world [1]. Sub-Saharan Africa records the highest rates of under-five child mortality in the world, 98 deaths per 1,000 live births. This figure is 15 times the average for developed countries [1].

The 2007 State of the World's Children Report documented that Nigeria is the country with the 14th highest under-five mortality rate in the world [2]. Seven years after, the 2014 edition of the same report ranked Nigeria as the country with the 9th highest under-five mortality rate in the world, with 124 under-five children dying per 1,000 live births. Incidentally, some African countries fare better; for instance, according to the 2014 report, Libya with an underfive mortality of 15/1000 ranks 116th and Seychelles with 13/1,000 live births ranks 125th. Some of the West African countries that have fared better than Nigeria include Senegal and Ghana with under-five mortality rates of $60 / 1,000$ and $72 / 1,000$ live births and ranking of 43 and 36, respectively $[2,3]$.

Earlier studies on childhood morbidity and mortality and child survival strategies in Nigeria presented some noteworthy findings. According to Policy Project/Nigeria office, the main causes of infant and child mortality in Nigeria include pneumonia, malaria, diarrhea, undernutrition, and vaccine-preventable diseases [4]. 
Malaria has been reported as the leading cause of childhood morbidity and mortality in Nigeria, accounting for $25 \%$ of infant and $30 \%$ of childhood mortality [5, 6]. A study among children in Ilorin, Nigeria, found that pneumonia accounted for $13.3 \%$ of all hospital admissions during the study period with a male : female ratio of $1.5: 1$ and $60.5 \%$ of the children were infants [7].

Inadequate knowledge and practice of child survival strategies by caregivers, as well as myths and misconceptions, contribute to child morbidity and mortality. A study by Tobin et al. found that $90.2 \%$ of respondents indicated that when a child is being weaned from breast milk, the child should continue with breastfeeding when diarrhea occurs with $9.8 \%$ indicating that breastfeeding should be discontinued with the onset of diarrhea [8]. In a study in Sokoto, Nigeria, Abiola et al. found that $32.4 \%$ of mothers studied believed that "evil eye" was the cause of diarrhea [9].

Worried about the alarming under-five mortality rates in developing countries, the WHO in collaboration with UNICEF and the World Bank, developed a set of evidencebased interventions which, when properly implemented, would reduce under-five mortality. This package of interventions was named child survival strategies. Originally, there were four child survival strategies, namely, growth monitoring, oral rehydration therapy, breastfeeding, and immunization, giving the acronym "GOBI" [10]. With time, some other interventions like family planning, female education, food supplementation, and vitamin A administration were added, giving the acronym GOBIFFFA [11].

Currently, child survival centers around newer strategies such as antenatal care attendance, skilled birth attendance at delivery, and commencement of breastfeeding within one hour of delivery. Others include use of insecticide treated bed nets, management of fever, and treatment of acute respiratory infections, amongst others. According to the NDHS 2013 and the National Bureau of Statistics 2014, the percentage of women who had four or more antenatal clinic visits in Cross River State, 58.7\%, was lower than the regional figure of $62.7 \%$ but higher than the national figure of $51.1 \%[12,13]$. Similarly, the percentage of children with fever for whom advice or treatment was sought from a health facility or provider was $21.0 \%$ which was lower than the regional figure of $28.2 \%$ and the national figure of $31.8 \%$ for males and $31.1 \%$ for females. However, Cross River State fared better in childhood immunization as the percentage of children aged 12-23 months who received specific vaccines at any time before the survey was higher than the national figures for the three vaccines considered, namely, BCG, DPT3, and OPV3.

\section{Aim of the Study}

The aim of this study was to determine the knowledge and practice of child survival strategies among rural community women in Cross River State, Nigeria.

\section{Materials and Methods}

3.1. Study Area. The study was carried out in Cross River State of Nigeria. Cross River State is one of the six states in
Nigeria's South-South geopolitical zone. With a population of over 3 million, Cross River State is made up of 18 Local Government Areas which are further grouped into three senatorial districts. The low socioeconomic status of rural community dwellers in Cross River State influences the health-seeking behavior of the women both for themselves and for children in their care.

3.2. Study Design. This was a descriptive cross-sectional study.

3.3. Sample Size Determination and Sample Selection. The sample size for the study was calculated using Leslie Kish formula:

$$
n=\frac{z^{2} p q}{d^{2}}
$$

In a study by Tobin et al., $90.2 \%$ of respondents were of the opinion that a child being weaned from breast milk should continue to receive the same when he/she has diarrhea [8]. Thus, the proportion with the desired positive attribute was taken as 0.902 .

Thus

$$
n=\frac{(1.96 \times 1.96 \times 0.902 \times 0.098)}{0.0025}=135
$$

Making provision for $10 \%$ nonresponse, the sample size became

$$
n=135+13.5=148.5 \text { or approximately, } 150 .
$$

Convenience sampling method was used to select 150 rural women. A questionnaire was used to collect data from them. The variables in the questionnaire included sociodemographic variables like age, marital status, occupation, religion, educational status, and ethnic grouping. Other variables included knowledge of the strategies that facilitate child survival and practice of the different child survival strategies. Data obtained from the respondents were analyzed using SPSS software version 20. Both univariate and bivariate analysis were performed. Association between categorical variables was explored using Chi square test.

3.3.1. Ethical Consideration. The data for this study were collected in accordance with the Declaration of Helsinki. Informed consent was obtained from the respondents.

\section{Results}

4.1. Sociodemographic Variables. Twenty-six percent of the respondents were aged 45 and above while over $90 \%$ were Christians. Nearly $19 \%$ of the respondents were civil servants while only $8 \%$ were full-time housewives. Sixty-percent of the respondents were married. Fifty-four (36\%) respondents had tertiary education. The Efiks constituted majority of the respondents, 77 (51.3\%) (Table 1$)$.

4.2. Knowledge of Child Survival Strategies and Sources of Information. As shown in Tables 2, 3, and 4, the child survival 
TABLE 1: Sociodemographic characteristics.

\begin{tabular}{lcc}
\hline Variable & Frequency $(n=150)$ & Percent \\
\hline Age group & 12 & \\
$15-19$ & 18 & 12.0 \\
$20-24$ & 18 & 12.0 \\
$25-29$ & 18 & 12.0 \\
$30-34$ & 28 & 18.7 \\
$35-39$ & 17 & 11.3 \\
$40-44$ & 39 & 26 \\
45 and above & & \\
\hline Religion & 142 & 94.7 \\
Christianity & 8 & 5.3 \\
Others & & \\
\hline Educational status & 12 & 8.0 \\
Nonformal & 22 & 14.7 \\
Primary & 62 & 41.3 \\
Secondary & 54 & 36.0 \\
Tertiary & & \\
\hline Occupation & 24 & 16.0 \\
Farming & 27 & 18.0 \\
Trading & 29 & 19.3 \\
Civil servant & 24 & 16 \\
Student & 12 & \\
Full-time housewife & & \\
Other & & \\
\hline
\end{tabular}

TABLE 2: Knowledge of child survival strategies.

\begin{tabular}{lcc}
\hline $\begin{array}{l}\text { Components of child } \\
\text { survival strategies } \\
\text { correctly indicated }\end{array}$ & Frequency $^{*}$ & Percent \\
\hline Growth monitoring & 64 & 42.7 \\
Oral rehydration therapy & 147 & 98 \\
Breastfeeding & 94 & 62.7 \\
Immunization & 101 & 67.3 \\
Family planning & 65 & 43.3 \\
Female education & 110 & 73.3 \\
Food supplementation & 40 & 26.7 \\
Essential drugs program & 34 & 22.7 \\
Treatment of common & 64 & 42.7 \\
ailments & & \\
\hline
\end{tabular}

${ }^{*}$ Multiple responses allowed.

strategy known to almost all of the respondents was oral rehydration therapy, 147 (98\%), followed by female education, 110 (73.3\%), and immunization, 101 (67.3\%). The commonest source of information regarding child survival strategies indicated by the respondents was health talk in health facility, 113 (75.3\%). Only 30 (20\%) respondents had adequate knowledge of frequency of weighing a child. One hundred and ten (73.3\%) respondents knew that vitamin A prevents blindness among children. The majority of respondents, 114 (76\%), knew that breastfeeding should be commenced within the first hour of birth just as the majority, 119 (79.3\%),
TABLE 3: Source of information.

\begin{tabular}{lcc}
\hline Source & Frequency $^{*}$ & Percent \\
\hline Health talks in hospital/health center & 113 & 75.3 \\
Personal advice by health worker & 77 & 51.3 \\
Health books & 43 & 28.7 \\
Radio/TV & 60 & 40 \\
Village health worker & 41 & 27.3 \\
Friends and relatives & 32 & 21.3 \\
Patent medicine vendor & 7 & 4.7 \\
Traditional birth attendant & 21 & 14 \\
\hline
\end{tabular}

${ }^{*}$ Multiple responses allowed.

TABLE 4: Adequacy of knowledge of child survival strategies.

\begin{tabular}{lcc}
\hline & \multicolumn{2}{c}{ Correct response } \\
Aspect of knowledge & $\begin{array}{c}\text { Frequency } \\
(n=150)\end{array}$ & Percent \\
\hline $\begin{array}{l}\text { Frequency of weighing of child } \\
\text { Vitamin that prevents blindness }\end{array}$ & 30 & 20 \\
$\begin{array}{l}\text { Food that contains vitamin D } \\
\text { When to commence }\end{array}$ & 67 & 73.3 \\
$\begin{array}{l}\text { breastfeeding } \\
\text { Should a child be given first } \\
\text { milk? }\end{array}$ & 114 & 44.7 \\
$\begin{array}{l}\text { Name of the first milk from } \\
\text { mother's breast after childbirth }\end{array}$ & 119 & 76 \\
$\begin{array}{l}\text { When should first polio vaccine } \\
\text { be given? }\end{array}$ & 105 & 79.3 \\
$\begin{array}{l}\text { What is exclusive breastfeeding? } \\
\text { Give salt sugar solution if child } \\
\text { has diarrhea }\end{array}$ & 117 & 84 \\
$\begin{array}{l}\text { Continue breastfeeding if child } \\
\text { has diarrhea }\end{array}$ & 123 & 70 \\
\hline
\end{tabular}

agreed that a child should be given the first milk that the mother expresses after childbirth. Similarly, the majority of respondents, 123 (82\%), knew that children should be given salt sugar solution when they have diarrhea. Only 49 (32.7\%) respondents knew that breastfeeding should be continued even if the child has diarrhea.

4.3. Practice of Child Survival Strategies. As shown in Table 5, sixty-two percent of respondents had attended antenatal clinic in the last pregnancy while $88 \%$ indicated that their last children had received all age-appropriate vaccinations. With regard to child spacing, $74 \%$ of respondents indicated that the interval between their last two deliveries was at least 2 years while $25 \%$ practiced exclusive breastfeeding of their last children.

4.4. Some Myths and Misconceptions regarding Certain Aspects of Child Survival. Figure 1 shows that thirty-one respondents indicated various reasons why colostrum should not be given to the baby; 15 (48.4\%) of these indicated that "it is not good for the child's health," 6 (19.4\%) indicated that "it is not 


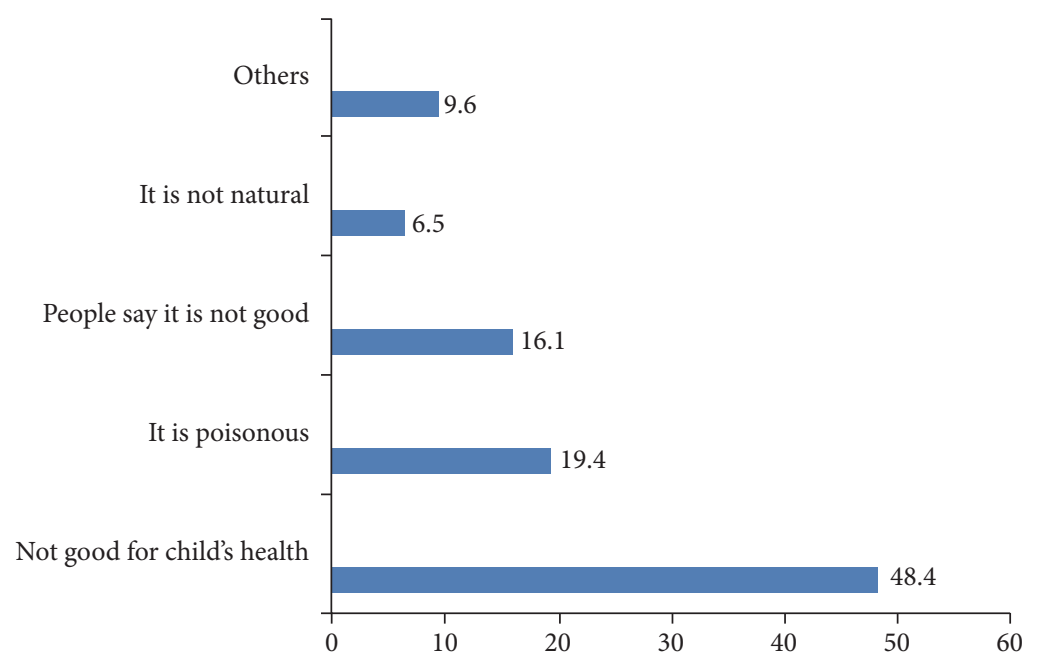

FIGURE 1: False beliefs about colostrum by respondents.

TABLE 5: Practice of child survival strategies in the last pregnancy and childbirth.

\begin{tabular}{lcc}
\hline $\begin{array}{l}\text { Child survival strategy } \\
\text { practiced }\end{array}$ & Frequency & Percent \\
\hline $\begin{array}{l}\text { Antenatal clinic } \\
\text { attendance }\end{array}$ & 93 & 62 \\
$\begin{array}{l}\text { Last child received all } \\
\text { immunizations }\end{array}$ & 137 & 88 \\
$\begin{array}{l}\text { At least 2-year interval } \\
\text { between last two } \\
\text { deliveries }\end{array}$ & 111 & 74 \\
$\begin{array}{l}\text { Exclusively breastfed last } \\
\text { child }\end{array}$ & 38 & 25 \\
$\begin{array}{l}\text { Given antimalarial in the } \\
\text { last pregnancy }\end{array}$ & 126 & 84 \\
\hline
\end{tabular}

natural," 2 (6.5\%) indicated that "it is poisonous," $5(16.1 \%)$ indicated that "people say it is not good," and 3 (9.6\%) gave various other reasons.

4.5. Association between Level of Education and Knowledge of Child Survival Strategies. Table 6 shows that more respondents with tertiary education (57.4\%) knew that growth monitoring is a child survival strategy compared with those with secondary education (38.7\%), primary education $(31.8 \%)$, and nonformal education (16.7\%). The difference in response between the four categories was statistically significant (Chi square $=9.568, \mathrm{df}=3, P=0.022)$. Similarly, all respondents with tertiary education (100\%) knew that oral rehydration therapy is a child survival strategy compared with $98.4 \%$ with secondary education, $95.5 \%$ with primary education, and 91.7\% with nonformal education. There was no statistically significant difference in the response from the four groups $(P=0.1289)$.
4.6. Association between Level of Education and Practice of Child Survival Strategies. Table 7 shows that more respondents with tertiary education (66.7\%) attended antenatal clinic in the last pregnancy than those with secondary education, (61.3\%), primary education (59.1\%), and nonformal education (50\%). There was no statistically significant difference between respondents in the four levels of education (Chi square $=1.325 ; \mathrm{df}=3 ; P=0.734)$. Similarly, all respondents with tertiary education (100\%) indicated that their last children had received all vaccinations. When this was compared with respondents who had only secondary education (93.5\%), primary education $(77.3 \%)$, and nonformal education $(66.7 \%)$, there was a statistically significant difference in the response between the four groups (Fisher's Exact Test, $\mathrm{df}=3 ; P=0.001)$. More respondents with nonformal education (83.3\%) practiced exclusive breastfeeding of the last child compared to respondents with primary education $(77.3 \%)$, secondary education $(74.2 \%)$, and tertiary education $(72.2 \%)$. However, there was no statistically significant difference in the response between the four groups (Chi square $=0.733$; $\mathrm{df}=3 ; P=0.884$ ). . More respondents with tertiary education $(87 \%)$ were likely to have interval between the last two deliveries equal to or greater than two years compared to those with secondary education (79\%), primary education (54.5\%), and nonformal education (25\%). The difference between the responses from the four groups was statistically significant (Chi square $=24.889$; $\mathrm{df}=3 ; P=$ 0.000).

4.7. Association between Knowledge and Practice of Child Survival Strategies. As shown in Table 8, children of respondents who indicated that immunization is a child survival strategy were more likely to have been fully immunized than children of those who did not and the difference was statistically significant $\left(\chi^{2}=23.02 ; \mathrm{df}=1 ; P=0.0000\right)$. There was no statistically significant association between knowledge of the correct definition of family planning and adequate spacing of the last two deliveries. 
TABLE 6: Association between level of education and knowledge of child survival strategies.

\begin{tabular}{|c|c|c|c|c|c|}
\hline \multirow{2}{*}{ Independent variable } & \multicolumn{2}{|c|}{ Dependent variable } & \multirow{2}{*}{ Test statistic } & \multirow{2}{*}{ df } & \multirow{2}{*}{$P$} \\
\hline & Yes & No & & & \\
\hline Level of education & \multicolumn{2}{|c|}{ Growth monitoring } & \multirow{5}{*}{$\begin{array}{c}\text { Chi square }= \\
9.568\end{array}$} & \multirow{5}{*}{3} & \multirow{5}{*}{0.022} \\
\hline Nonformal & $2(16.7 \%)$ & $10(83.3 \%)$ & & & \\
\hline Primary & $7(31.8 \%)$ & $15(68.2 \%)$ & & & \\
\hline Secondary & $24(38.7 \%)$ & $38(61.3 \%)$ & & & \\
\hline Tertiary & $31(57.4 \%)$ & $23(42.6 \%)$ & & & \\
\hline Level of education & \multicolumn{2}{|c|}{ Oral rehydration therapy } & \multirow{5}{*}{$\begin{array}{c}\text { Fisher's Exact } \\
\text { Test }\end{array}$} & \multirow{5}{*}{3} & \multirow{5}{*}{0.1289} \\
\hline Nonformal & $11(91.7 \%)$ & $1(8.3 \%)$ & & & \\
\hline Primary & $21(95.5 \%)$ & $1(4.5 \%)$ & & & \\
\hline Secondary & $61(98.4 \%)$ & $1(1.6 \%)$ & & & \\
\hline Tertiary & $54(100 \%)$ & $0(0 \%)$ & & & \\
\hline Level of education & \multicolumn{2}{|c|}{ Breastfeeding } & \multirow{5}{*}{$\begin{array}{c}\text { Chi square }= \\
2.863\end{array}$} & \multirow{5}{*}{3} & \multirow{5}{*}{0.418} \\
\hline Nonformal & $6(50 \%)$ & $6(50 \%)$ & & & \\
\hline Primary & $12(54.5 \%)$ & $10(45.5 \%)$ & & & \\
\hline Secondary & $38(61.3 \%)$ & $24(38.7 \%)$ & & & \\
\hline Tertiary & $38(70.4 \%)$ & $16(29.6 \%)$ & & & \\
\hline Level of education & \multicolumn{2}{|c|}{ Immunization } & \multirow{5}{*}{$\begin{array}{c}\text { Chi square }= \\
7.210\end{array}$} & \multirow{5}{*}{3} & \multirow{5}{*}{0.066} \\
\hline Nonformal & $6(50 \%)$ & $6(50 \%)$ & & & \\
\hline Primary & $12(54.5 \%)$ & $10(45.5 \%)$ & & & \\
\hline Secondary & $40(64.5 \%)$ & $22(35.5 \%)$ & & & \\
\hline Tertiary & $43(79.6 \%)$ & $11(20.4 \%)$ & & & \\
\hline Level of education & \multicolumn{2}{|c|}{ Family planning } & \multirow{5}{*}{$\begin{array}{c}\text { Chi square }= \\
6.659\end{array}$} & \multirow{5}{*}{3} & \multirow{5}{*}{0.084} \\
\hline Nonformal & $4(33.3 \%)$ & $8(66.7 \%)$ & & & \\
\hline Primary & $5(22.7 \%)$ & $17(77.3 \%)$ & & & \\
\hline Secondary & $27(43.5 \%)$ & $35(56.5 \%)$ & & & \\
\hline Tertiary & $29(53.7 \%)$ & $25(46.3 \%)$ & & & \\
\hline
\end{tabular}

\section{Discussion}

Only $32.7 \%$ of respondents knew that breastfeeding should be continued even when the child has diarrhea. This is comparable to the finding by Tobin et al. that $35.3 \%$ of respondents in a related study in a rural community in SouthSouth Nigeria indicated that a child that has diarrhea should be given more breast milk than usual [8]. The findings of these two studies reflect a deficiency in the knowledge and skill of home management of diarrhea among the respondents and are comparable to the finding of a study by Adimora et al. that only $39.4 \%$ of mothers of under-five children could correctly manage diarrhea at home while majority $(60.6 \%)$ could not [14]. The finding of this study is also comparable to that of a related study where Okoh and Alex-Hart found that only $29.3 \%$ of respondents had good level of knowledge of home management of diarrhea while only $33.8 \%$ had good level of skill [15].

The majority of respondents, $79.3 \%$, agreed that the baby should be given colostrum. This is contrary to the findings of Walia et al. where $66 \%$ of respondents withheld colostrums from neonates [16]. In a related study, Morse et al. found that, in 50 out of 120 cultural groups studied, initiation of breastfeeding was delayed by more than 2 days, thus withholding colostrum from the baby [17]. The idea that colostrum is not natural, as indicated by $19.4 \%$ of respondents, may be associated with the concept of witch's milk which is the local name given to the milk produced by the breasts of infants. This milk is believed to be abnormal and ancient folklore has blamed it as a source of nourishment for witches' familiar spirits [18]. The close resemblance of colostrum to the socalled witch's milk may explain why the respondents indicate that it is not natural [18]. Regarding reasons why colostrums should not be given to infants, in the study by Walia et al., $54.5 \%$ of respondents indicated that it causes obstructions in the intestine while $24.3 \%$ indicated that it would be difficult to digest [16].

The proportion of respondents who had antenatal care in the last pregnancy (62\%) is comparable to the national average of $61 \%$ reported by NDHS 2013 [12]. The high ANC attendance in the state may be due to the free health care for pregnant women and under-five children instituted by the Cross River State Government [19]. Nearly all respondents (98\%) knew that ORT is a child survival strategy. This is not surprising because, in Cross River State, the populace is so familiar with salt sugar solution that they even have an apt local name for it, "mmong uwem," which means "life giving 
TABLE 7: Association between level of education and practice of child survival strategies.

\begin{tabular}{|c|c|c|c|c|c|}
\hline \multirow{2}{*}{ Independent variable } & \multicolumn{2}{|c|}{ Dependent variable } & \multirow{2}{*}{ Test statistic } & \multirow{2}{*}{$\mathrm{df}$} & \multirow{2}{*}{$P$} \\
\hline & Yes & No & & & \\
\hline Level of education & \multicolumn{2}{|c|}{ Attended antenatal care } & \multirow{5}{*}{$\begin{array}{c}\text { Chi square }= \\
1.325\end{array}$} & \multirow{5}{*}{3} & \multirow{5}{*}{0.734} \\
\hline Nonformal & $6(50 \%)$ & $6(50 \%)$ & & & \\
\hline Primary & $13(59.1 \%)$ & $9(40.9 \%)$ & & & \\
\hline Secondary & $38(61.3 \%)$ & $24(38.7 \%)$ & & & \\
\hline Tertiary & $36(66.7 \%)$ & $18(33.3 \%)$ & & & \\
\hline Level of education & \multicolumn{2}{|c|}{ Child received immunizations } & \multirow{5}{*}{$\begin{array}{c}\text { Fisher's Exact } \\
\text { Test }\end{array}$} & \multirow{5}{*}{3} & \multirow{5}{*}{0.001} \\
\hline Nonformal & $8(66.7 \%)$ & $4(33.3 \%)$ & & & \\
\hline Primary & $17(77.3 \%)$ & $5(22.7 \%)$ & & & \\
\hline Secondary & $58(93.5 \%)$ & $4(6.5 \%)$ & & & \\
\hline Tertiary & $54(100 \%)$ & $0(0 \%)$ & & & \\
\hline Level of education & \multicolumn{2}{|c|}{ Interval between deliveries $\geq 2$ years } & \multirow{5}{*}{$\begin{array}{c}\text { Chi square }= \\
24.889\end{array}$} & \multirow{5}{*}{3} & \multirow{5}{*}{0.000} \\
\hline Nonformal & $3(25 \%)$ & $9(75 \%)$ & & & \\
\hline Primary & $12(54.5 \%)$ & $10(45.5 \%)$ & & & \\
\hline Secondary & $49(79 \%)$ & $13(21 \%)$ & & & \\
\hline Tertiary & $47(87 \%)$ & $7(13 \%)$ & & & \\
\hline Level of education & \multicolumn{2}{|c|}{ Exclusive breastfeeding } & \multirow{5}{*}{$\begin{array}{c}\text { Chi square }= \\
0.733\end{array}$} & \multirow{5}{*}{3} & \multirow{5}{*}{0.884} \\
\hline Nonformal & $10(83.3 \%)$ & $2(16.7 \%)$ & & & \\
\hline Primary & $17(77.3 \%)$ & $5(22.7 \%)$ & & & \\
\hline Secondary & $46(74.2 \%)$ & $16(25.8 \%)$ & & & \\
\hline Tertiary & $39(72.2 \%)$ & $15(27.8 \%)$ & & & \\
\hline Level of education & \multicolumn{2}{|c|}{ Being given antimalarial medicine during pregnancy } & \multirow{5}{*}{$\begin{array}{c}\text { Fisher's Exact } \\
\text { Test }\end{array}$} & \multirow{5}{*}{3} & \multirow{5}{*}{0.023} \\
\hline Nonformal & $7(58.3 \%)$ & $5(41.7 \%)$ & & & \\
\hline Primary & $16(72.7 \%)$ & $6(27.3 \%)$ & & & \\
\hline Secondary & $55(88.7 \%)$ & $7(11.3 \%)$ & & & \\
\hline Tertiary & $48(88.9 \%)$ & $6(11.1 \%)$ & & & \\
\hline
\end{tabular}

TABLE 8: Association between knowledge and practice of child survival strategies.

\begin{tabular}{|c|c|c|c|c|c|}
\hline Knowledge variable & & & df & Chi square & $P$ value \\
\hline \multirow{2}{*}{ Immunization as a child survival strategy } & & & \multirow{4}{*}{1} & \multirow{4}{*}{23.02} & \multirow{4}{*}{0.0000} \\
\hline & Yes & No & & & \\
\hline Yes & 100 & 1 & & & \\
\hline No & 37 & 12 & & & \\
\hline \multirow{2}{*}{ Correct definition of exclusive breastfeeding } & st chi & stfed & & \multirow{4}{*}{19.087} & \multirow{4}{*}{0.0000} \\
\hline & Yes & No & \multirow{3}{*}{1} & & \\
\hline Yes & 20 & 97 & & & \\
\hline No & 18 & 15 & & & \\
\hline \multirow{2}{*}{ Correct definition of family planning } & etwee & at lec & \multirow{4}{*}{1} & \multirow{4}{*}{2.44} & \multirow{4}{*}{0.1180} \\
\hline & Yes & No & & & \\
\hline Yes & 31 & 6 & & & \\
\hline No & 80 & 33 & & & \\
\hline
\end{tabular}

water." This proportion is higher than that of a study by Sanusi and Gbadamosi which found that $78.3 \%$ of mothers in Oyo state, Nigeria, practiced ORT as a child survival strategy [20].

Education was found to be a determinant of knowledge and practice of some child survival strategies. It was a determinant of attendance of antenatal clinic although there was no statistically significant difference between the four levels of education $(P=0.734)$. A study by Joshi et al. showed that higher level of education was one of the predictors of both attendance at four or more antenatal visits and receipt of good quality care [21]. Education was a determinant of 
respondents' children having received all vaccinations, with children of respondents with tertiary education doing better than those of lower levels of education, with a statistically significant difference, $P=0.001$. Educated women may want to have fewer children that they can cater for (in terms of health and social amenities) and help the children to also be as educated as them.

There was an association between level of education and having received antimalarial medicine in the last pregnancy with a statistically significant difference, $P=0.023$. These findings compare favorably with those of the NDHS (2013) which documented that women with more than a secondary school education were more likely than other women to have received two or more tetanus toxoid injections during pregnancy. This positive effect of education on the quality of care obtained during antenatal care is further corroborated by another finding by NDHS 2013 that only 43 percent of women with no education used iron tablets or syrup, whereas 74 percent of women with a primary education, 86 percent of women with a secondary education, and 92 percent of women with more than a secondary education did so [12]. The observed inverse relationship between level of education and likelihood of exclusively breastfeeding the last child is likely because women with a higher level of education are more likely than those with lower levels to be employed in jobs that are so demanding that it is difficult for them to exclusively breastfeed their babies. One plausible reason why the breastfeeding prevalence recorded in this study $(25 \%)$ is higher than the national prevalence (17\%) is that $42 \%$ of respondents belong to the occupational category of farmers, traders, and full-time housewife. These occupations allow them more time to be within their communities and therefore have access to their babies for breastfeeding.

\section{Conclusion}

Respondents demonstrated adequate knowledge and practice of most of the child survival strategies, especially with regard to oral rehydration therapy. However, there was evidence of some gaps like majority of respondents not knowing that breastfeeding should be continued even when the child has diarrhea. Such inadequate knowledge and practice, including evidence of myths and misconceptions demonstrated by the respondents, could mar efforts to reduce child morbidity and mortality in the state. Education was associated with knowledge and practice of most child survival strategies. This may be an indication that the advocacy for girl child education, which has been intensified within the past 15 years, is gradually making the desired impact and should be encouraged. It is recommended that health care providers should do more to educate caregivers about the basic facts regarding child survival strategies.

\section{Competing Interests}

The authors declare that there is no conflict of interests regarding the publication of this paper.

\section{References}

[1] UNICEF, Levels and Trends in Child Mortality. Report 2013 Estimates Developed by the UN Inter Agency Group for Child Mortality Estimation, United Nations Children's Fund, New York, NY, USA, 2013.

[2] UNICEF, The State of the World's Children, 2007.

[3] UNICEF, The State of the World's Children, UNICEF, 2014.

[4] Policy Project/Nigeria, "Child Survival in Nigeria: Situation, Response, and Prospects Key Issues POLICY Project/Nigeria," October 2002, http://www.policyproject.com/pubs/countryreports/nig_csrevised.pdf.

[5] UNICEF Annual Report, "The inter-agency group for child mortality estimation (IGME). Estimates of under five mortality rates by country, the 2011 release," http://www.childmortality org/.

[6] FMOH, Training Manual for Management of Malaria in Nigeria, FMOH/National Malaria and Vector Control Division, Abuja, Nigeria, 2005.

[7] A. A. Abdulkarim, R. M. Ibraheem, A. O. Adegboye, W. B. R. Johnson, and M. A. N. Adeboye, "Childhood pneumonia at the University of Ilorin Teaching Hospital, Ilorin Nigeria," Nigerian Journal of Paediatrics, vol. 40, no. 3, pp. 284-289, 2013.

[8] E. A. Tobin, E. C. Isah, and D. A. Asogun, "Care giver's knowledge about childhood diarrheal management in a rural community in South-South Nigeria," International Journal of Community Research, vol. 3, no. 4, pp. 93-99, 2014.

[9] A. O. A. Abiola, A. L. Ndaman, S. H. Idris, N. M. Jiya, and M. T. O. Ibrahim, "Home management of childhood diarrhoea among mothers in Sokoto, Nigeria," Tropical Journal of Health Sciences, vol. 17, no. 1, 2015.

[10] The 1980s: Campaign for child survival, http://www.unicef.org/ sowc $96 / 1980$ s.htm.

[11] Choosing interventions to reduce specific risks, 2015, http:// www.who.int/whr/2002/chapter5/en/index5.html.

[12] National Population Commission (NPC) (Nigeria) and ICF International, Nigeria Demographic and Health Survey (NDHS) 2013, NPC and ICF International, Abuja, Nigeria, 2014.

[13] NBS/UNICEF/USAID, National Nutrition and Health Survey (NNHS), National Bureau of Statistics, Abuja, Nigeria, 2014.

[14] G. N. Adimora, A. N. Ikefuna, and G. Ilechukwu, "Home management of childhood diarrhoea: need to intensify campaign," Nigerian Journal of Clinical Practice, vol. 14, no. 2, pp. 237-241, 2011.

[15] B. A. N. Okoh and B. A. Alex-Hart, "Home management of diarrhoea by caregivers presenting at the diarrhoea training unit of a tertiary hospital in Southern Nigeria," British Journal of Medicine \& Medical Research, vol. 4, no. 35, pp. 5524-5540, 2014.

[16] I. Walia, R. Kalia, and S. Chopra, "Initiation of breast feedingthe cultural factors," Nursing and Midwifery Research Journal, vol. 5, no. 1, pp. 10-18, 2009.

[17] J. M. Morse, C. Jehle, and D. Gamble, "Initiating breastfeeding: a world survey of the timing of postpartum breastfeeding," International Journal of Nursing Studies, vol. 27, no. 3, pp. 303313, 1990 .

[18] Galactorrhea of the newborn (witch's milk), 2015, http://www .pediatricsconsultantlive.com/photoclinic/galactorrhea-newborn-witch $\% \mathrm{E} 2 \% 80 \% 99$ s-milk.

[19] CRSG, "Maternal health services," http://www.crossriverstate .gov.ng/index.php?option $=$ com_content $\&$ view $=$ article\&id $=152$ : maternal-health-services\&catid $=88$ :healthcare $\&$ Itemid $=754$. 
[20] R. A. Sanusi and A. O. Gbadamosi, "Do Mothers' knowledge and practice of 'Child Survival Strategies' affect the nutritional status of their children?" Pakistan Journal of Nutrition, vol. 8, no. 9, pp. 1506-1511, 2009.

[21] C. Joshi, S. Torvaldsen, R. Hodgson, and A. Hayen, "Factors associated with the use and quality of antenatal care in Nepal: a population-based study using the demographic and health survey data," BMC Pregnancy and Childbirth, vol. 14, article 94, 2014. 


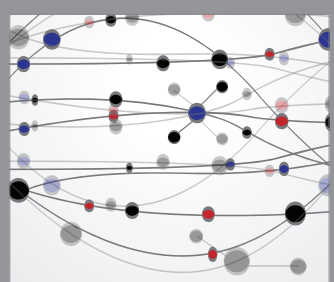

The Scientific World Journal
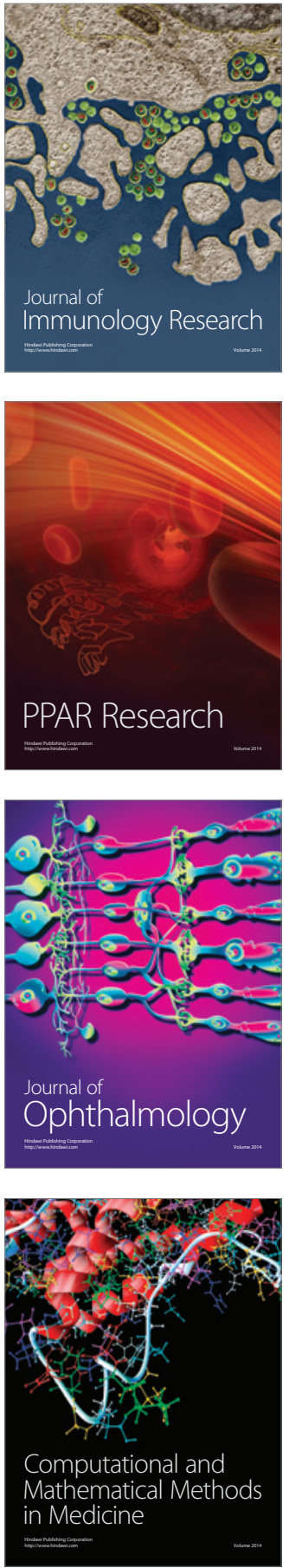

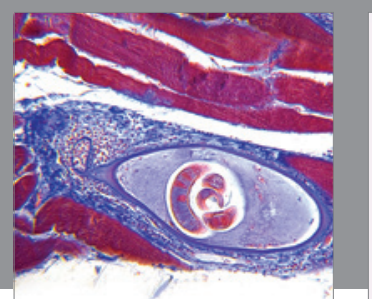

Gastroenterology Research and Practice

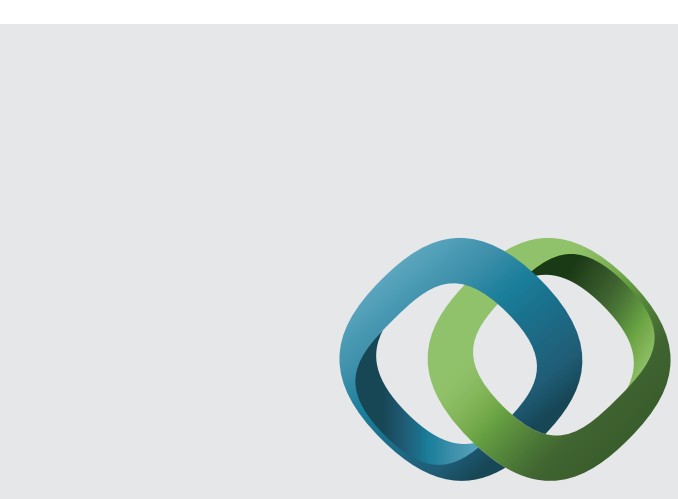

\section{Hindawi}

Submit your manuscripts at

http://www.hindawi.com
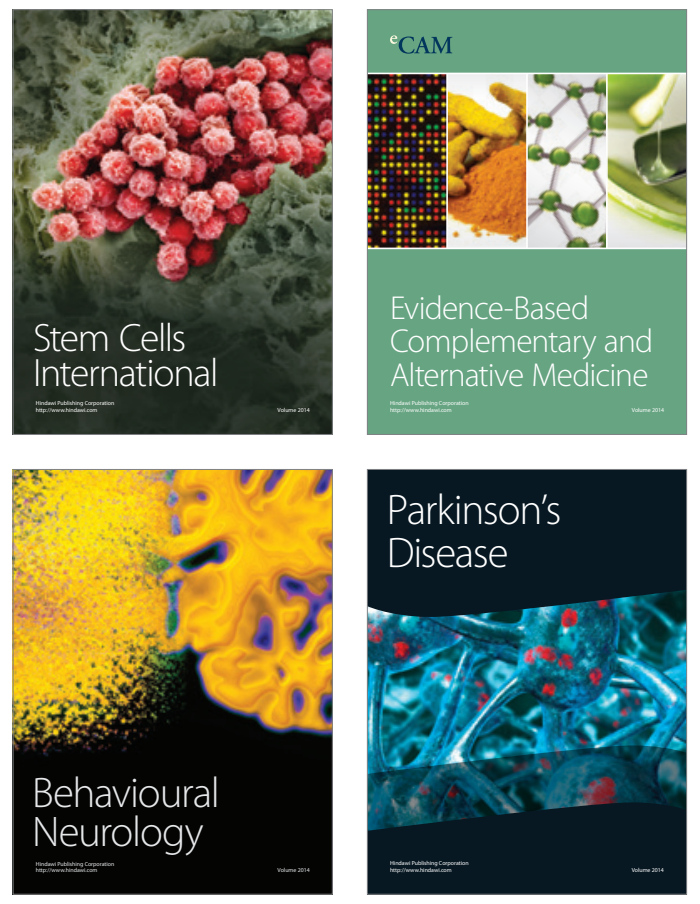
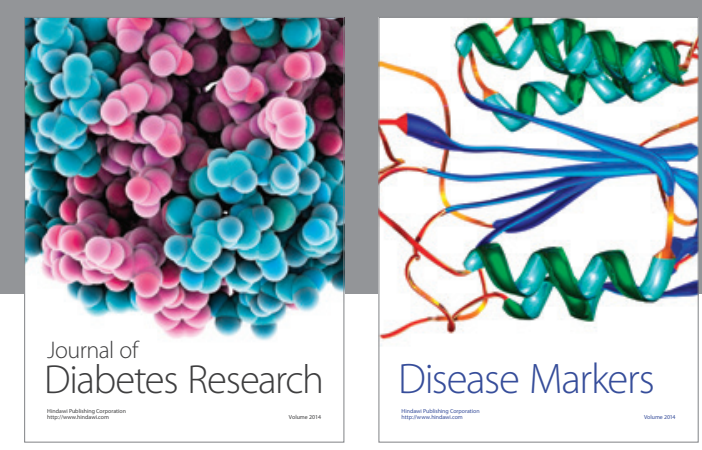

Disease Markers
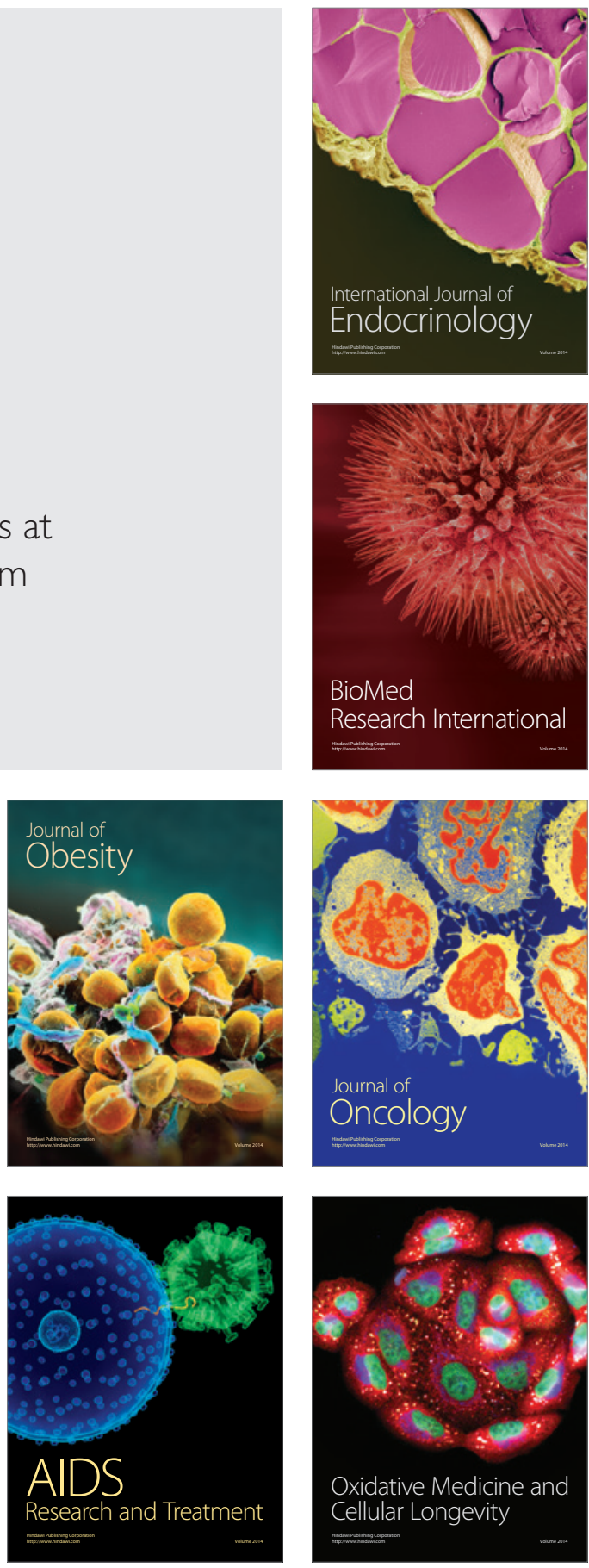